\title{
A Comparative Study of Vaginal Delivery Versus Caesarean Section In Primigravida with Eclampsia After 34 Weeks of Pregnancy.
}

\author{
Swaralipi Misra ${ }^{1}$,Swapan Das $^{2}$,Debjani Deb ${ }^{2}$,Biswajit Mahapatra ${ }^{3}$, \\ Anindya Kumar Das ${ }^{4}$ \\ ${ }^{I}$ Post Graduate Trainee, Dept. Of Obstetrics \& Gynaecology, Bankura Sammilani Medical College \& Hospital, \\ Bankura, West Bengal, India. \\ ${ }^{2}$ Assistant Professor, Dept. Of Obstetrics \& Gynaecology, Bankura Sammilani Medical College \& Hospital, \\ Bankura, West Bengal, India. \\ ${ }^{3}$ RMO cum Clinical Tutor, Dept. Of Obstetrics \& Gynaecology, Bankura Sammilani Medical College \& \\ Hospital, Bankura, West Bengal, India. \\ ${ }^{4}$ Professor, Dept. Of Obstetrics \& Gynaecology, Bankura Sammilani Medical College \& Hospital, Bankura, \\ West Bengal, India.
}

\begin{abstract}
Objective : To compare the results of vaginal delivery \& caesarean section in the management of antepartum eclampsia in primigravidae with more than 34 weeks by gestation, with reference to perinatal morbidity and mortality and maternal morbidity \& mortality.

Materials \& Methods: This institution based, descriptive study was conducted in the department of obstetrics \& Gynaecology, Bankura Sammilani Medicare College \& Hospital, Bankura during the period extending from February 2014 to January 2015. A total 100 eclamptic women who fulfilled the inclusion criteria \& had no factors mentioned in exclusion criteria were included in the study. Patients were divided into two groups for comparative analysis. The first group consisted of patients in whom conservative obstetric management and delivery per vaginum was carried out and was called the V.D. Group. The second group consisted of patients in whom lower segment caesarean section was carried out due to eclampsia and varied associated indications was called C.D. Group.

Conclusion: Maternal \& perinatal morbidity \& mortality were low in patient undergoing caesarean delivery than in vaginal delivery group. Both maternal and perinatal outcome can be improved by taking an early decision for caesarean section when the cervix is unfavourable on admission or delivery is not anticipated within 6 hours.
\end{abstract}

Keywords: Eclampsia, caesarean section, vaginal delivery.

\section{Introduction}

Eclampsia is a very serious complication of pregnancy responsible for high maternal and perinatal mortality. Eclampsia is a largely preventable condition and has becoming rare in developed countries.

The term eclampsia is derived from a Greek word, meaning "like a flash of lightening". ${ }^{[1]}$

The onset of convulsions in a woman with pre-eclampsia that cannot be attributed to other causes is termed eclampsia. ${ }^{[2]}$

The incidence in India ranges from 1 in 500 to 1 in 30. It is more common in primigravidae (75\%), five times more common in twins than in singleton pregnancies and occurs between the 36th week and term in more than 50\% [1] Eclampsia is an obstetric enigma. Though it has almost been eradicated from the developed world, it continues to be a major cause of maternal and fetal mortality and morbidity in the developing countries. The real challenge of eclampsia has not been met. In spite of considerable progress made in the field of obstetrics, the incidence of eclampsia and its consequent complications has not decreased significantly in our country over the past few decades. It is indeed sad that even today antenatal care is available only to a fraction of our rural population. However, the management of eclampsia still poses a fascinating challenge to the obstetrician, requiring the greatest skill, judgement and patience. ${ }^{[3]}$

Eclampsia is essentially a disease of low socio economic status of primigravida, a product of ignorance and neglect. Ideally, it is a preventable disease or almost so. But unfortunately its incidence is still uncomfortably high in any hospital accepting unbooked cases. Menon et.al (1989) quoted an incidence of $0.83 \%$ to $1.6 \%$ from leading centres of India.

Faced with this reality, a plan of management has to be evolved. Though the exact patho-physiology leading to the occurrence of fits is still not understood, one thing has been proved beyond doubt that termination 
of pregnancy, removes the basic cause of the disease. Keeping this in view an attempt has been made in the present study to ascertain if caesarean section has any distinct advantage over vaginal delivery in lowering maternal and perinatal deaths. ${ }^{[4]}$

\section{Aims And Objectives}

1) To evaluate the role of termination of pregnancy by caesarean section and termination by vaginal delivery in antepartum eclampsia occurring in primigravidae with more than 34 weeks gestation, with reference to perinatal morbidity and mortality and maternal morbidity and mortality.

2) Analyzepatient's age, gestational age, and types of complication, feto- maternal outcome and prognosis with respect to mode of delivery.

3) To compare the results of termination of pregnancy by caesarean section with those obtained by routine or induced vaginal delivery in primi with more than 34 weeks gestation with antepartum eclampsia, with reference to perinatal morbidity and mortality and maternal morbidity and mortality.

\section{Materials \& Methods}

This institution based, descriptive study was conducted in the department of Obstetrics \& Gynaecology, Bankura Sammilani Medical College \& Hospital, Bankura, during the period extended from February 2014 to January 2015. Permission for the study was duly obtained from Ethical Committee of Bankura Sammilani Medical College \& Hospital, Bankura.

A total 100 eclamptic women who fulfilled the inclusion criteria and had no factors mentioned in exclusion criteria were included in the study.

Inclusiion criteria were : Primigravida, Period of gestation > 34 weeks, Antepartum eclampsia.

Exclusion Criteria were : Patients with pregnancy induced hypertension without eclampsia and patients with epilepsy or other causes of convulsions with pregnancy.

Patients were divided into two groups for comparative analysis. The first group consisted of patients in whom conservative obstetrics management and delivery per vaginum was carried out and was called the 'V.D Group'. The second group consisted of patients in whom lower segment caesarean section was carried out due to eclampsia \& varied associated indications was called CD Group. Diagnostic criteria of eclampsia were highblood pressure $(>140 / 90 \mathrm{~mm}$ of $\mathrm{Hg}$ ), Significant proteinuria and convulsion associated with pregnancy more than 20 weeks of gestation. The purpose and procedure of the study was explained to the subjects who fulfilled the enrolment criteria. After taking informed written consent from the guardians of the patients, history was taken carefully and a through clinical examination was done. The urine was tested for protein. Convulsions were controlled by magnesium sulphate $\left(\mathrm{MgSO}_{4}\right)$ if not contraindicated and blood pressure was controlled by nifedipine and labetalol IV (only given in conscious patients). After initial management decision for termination of pregnancy was taken and mode of delivery (vaginal delivery or LSCS) was planned. The mode of delivery was noted and the patients were followed uptill discharge.

Paremeters for perinatal outcome were birth weight, APGAR Score, live or still birth, NICU admission and any complication. PPH Abrupptio placentae, CVA, Renal Failure, Pulmonary Oedema, fever, Haematuria, Electrolyte imbalance were considered as maternal complications.

All the relevant data for each patient were entered in MS Excel spread sheet. Calculated data were compiled and appropriate statistical analysis were done using computer based software SPSS 22.0 free version 'P' value $<0.05$ was taken as significant with $95 \%$ confident interval.

\section{Results}

Table - I shows distribution of study subjects as per their clinical profile. Average age of mothers with eclampsia was 21 yrs. Most of them had 3 convulsion on an average. Most of the mothers received less than 1 or no antenatal visit during their pregnancy. Glassgow coma scale on admission was around 12 for most of the mothers. Mean pulse rate was 80.76/ min , systolic BP was $149.74 \mathrm{~mm} \mathrm{Hg}$, Diastolic BP was 97.60mm Hg and Respiratory rate was $19.59 / \mathrm{min}$.

Table - II shows that vaginal delivery $(60.0 \%)$ was more than that of caesarean section $(40.0 \%)$.

Table - III shows distribution of Gestational age of study subjects according to mode of delivery. In gestational age of 34-37 weeks vaginal delivery (73.5\%) was more than caesarean section $(26.5 \%)$ wherein in gestational age of 37-40 weeks vaginal delivery (53\%) was slightly more than that of caesarean section (47\%). The incidence of caesarean section was less in 34-37 weeks of gestational age, whereas it was nearly about 50\% in 37-40 weeks of gestational age. Incidence of vaginal delivery was about $2 / 3^{\text {rd }}$ in $34-37$ weeks of GA and nearly $1 / 2$ in 37-40 weeks of GA, however the difference was statistically just significant $(\mathrm{P}<0.05)$.

Table IV shows distribution of study population as per their indication of caesarean section. Proportion of indication of caesarean section were most for cervical factors (35\%) and fetal distress (30\%) followed by abnormal labour $(25 \%)$ and least by Antepartum eclampsia per se i.e. $10 \%$. 
Table $-\mathbf{V}$ shows that the convulsion delivery interval was less than 6 hours in $76.9 \%$ of the cases in the caesarean section group followed by 6-12 hrs, then > $24 \mathrm{hrs}$, then 12-18 hours and least by 18-24 hrs interval. Whereas in the vaginal delivery group the convulsion delivery interval was most in 18-24 hrs followed by $12-18 \mathrm{hrs}$, then $>24 \mathrm{hrs}$, then 6-12 hrs and least by 0-6 hrs, however the difference for convulsion delivery interval among the two groups was statistically significant. $(\mathrm{P}<0.05)$.

Table - VI shows distribution of perinatal outcome between the two study groups. Number of study subjects were 60 in vaginal delivery group and total number of babies were 62 including 2 cases of twin gestation whereas in caesarean section group were 40 and total number of babies were 41 including 1 case of twin pregnancy. Proportion of IUGR (30.64\%), LBW (14.51\%) and prematurity $(64.51 \%)$ was more in vaginal delivery group than in caesarean section group which was $9.51 \%, 12.20 \%$ and $36.58 \%$ respectively. Proportion of new born with Apgar score less than 5 at 1 min was more in vaginal delivery group (45.61\%) than caesarean section group $(34.14 \%)$. Proportion of newborn which need resuscitation was more in vaginal delivery group $(24.19 \%)$ than caesarean section group $(9.75 \%)$. Proportion of new born which need NICU for treatment was more in vaginal delivery group $(41.93 \%)$ than caesarean section group $(29.26 \%)$. Live birth was more in caesarean section group (97.56\%) than in vaginal delivery group (80.64\%). Still birth was more in vaginal delivery group $(19.35 \%)$ than in caesarean section group $(2.43 \%)$. Early neonatal death was more in vaginal delivery group $(12.9 \%)$ than in caesarean section group $(9.75 \%)$. Uncorrected perinatal mortality was more in vaginal delivery group (32.25\%) than in caesarean section group (12.19\%). Corrected perinatal mortality rate in vaginal delivery group was $24.19 \%$ and in caesarean section group it was $12.19 \%$

Table VII shows that maternal complications were significantly higher among women in vaginal delivery group (60\%) compared to caesarean section group (15\%).

Table - VIII shows distribution of maternal mortality according to mode of delivery. There were no maternal death in caesarean section group whereas 2 deaths in vaginal delivery group.

\section{Discussion}

In our study the incidence of caesarean section was $40 \%$ and that of vaginal delivery was $60 \%$. This was comparable with the study of Mario Lopezllera (5) who in their series of 107 cases found the incidence of caesarean section to be $40.4 \%$. In the present study the higher incidence of antepartum eclampsia in both the groups was found in the age group of 20-25 years. This is comparable with the studies conducted by Hakerwadi et.al (6) in 1996 of Vinita Bansal et. Al (7) in 1998.

In our study the highest incidence was found between 37 to 40 weeks (66\% of the total) of which 47 in the CD group \& 53\% in the V.D Group. But it is not supported by the study conducted by low JJ et.al (8) in 1995 and Mundle S et.al (9) in 1998. They found maximum incidence (60-70\%) between 33 to 36 weeks. In our hospital most of the referrals constituted term gestations with viable fetus and poor cervical scores. As our hospital was tertiary centre for both maternal and neonatal care, these patients were referred from nearby nursing homes to improve neonatal outcome. This was probably the reason why majority of our patients had gestational ages between 37 to 40 weeks.

In our study $10 \%$ of the cases were operated for antepartum eclampsia per se. Cervical factors topped the list of indication for caesarean section, accounting for $35 \%$ of the cases. The next commonest indication was fetal distress, accounting for $30 \%$ of the cases. Hakerwadi et.al (6) quoted faetal distress in $36.18 \%$ of the sectioned patient followed by failed induction in $20.6 \%$, Habeebullah $\mathrm{S}$ et.al (10) quoted $34.7 \%$ incidence of faetal distress.

Regarding perinatal morbidity in our study, it was seen that APGAR score at 1 min was less than 5 in $34.14 \%$ of the cases in the CD group and in $45.16 \%$ of the cases in the VD Group, most of the babies born vaginally being asphyxiated. Even the NICU admission rates showed in notable difference i.e. $29.26 \%$ in the CD group and $41.93 \%$ in the V.D Group. It is considerable to note that the babies in the CD Group that required NICU admission were either cases of induction failure or cases admitted after trials at primary health centres. None of the cases operated within 6 hours of the first fit required NICU admission.

Regarding perinatal mortality the incidence in CD and VD Group of live birth was $97.56 \%$ and $80.64 \%$ respectively, of still birth was $2.43 \%$ and $19.35 \%$ respectively and that of neonatal death was $9.75 \%$ and $12.9 \%$ respectively.

The striking difference in the incidence of live birth \& still birth in the two groups could be partly attributed to the comparatively increased rates of IUGR, low birth weight and preterm babies in the V.D. Group. However still the difference was considerable.

The corrected PNM figure in the CD and VD groups were $12.19 \%$ and $24.19 \%$ respectively. This was comparable with the study conducted by Dandekar L. M et. al in 1992.

In our study maternal complication were encountered in $15 \%$ of the cases in the CD Group and $50 \%$ of the cases in the V.D. group. Among the maternal complications post partum haemorrhage was seen in $15 \%$ of the cases in the V.D. Group, all of which were controlled with oxytocin \& Prostodin except one who developed 
DIC and succumbed to death. On the other hand, 1 case in the C.D. Group has post partum haemorrhage intra operatively but was controlled with B-Lynch suture.

Abraptio placentae was seen in $3.33 \%$ of the cases in the V.D. Group. However, they improved after blood transfusion. Hakerwadi AV et. el (6) quoted an incidence of 19.6\% and Sibai et.al (12) in 1993 quoted an incidence of $20 \%$ in eclampsia.

Acute Renal failure was seen in $3.33 \%$ of the cases in the V.D. Group. One case improved after dialysis while the other not responding to dialysis, died on the $6^{\text {th }}$ postnatal day. Collaborative Eclampsia Trial group (13) in 1995 quoted an incidence of $4.5 \%$ of ARF out of 110 maternal death due to eclampsia.

CVA was seen in $6.66 \%$ of the cases in the V.D. group. Sheehan \& Lynch (14) in 1973 reported an incidence of $10.09 \%$ for cerebral haemorrhage in eclampsia.

Pulmonary oedema was seen in $3.33 \%$ of the cases in the V.D. Group in our study. They all responded well to oxygen therapy \& diuretics. Bansal V et.al in 1998 found the incidence to be $4.6 \%$.

In our study fever was encountered in $5 \%$ of the cases in the CD Group and $8.33 \%$ of the cases in the VD Group which subsided within 48 hours with antipyretics. Group.

In our study Haematuria is seen in $8.33 \%$ of the cases in V.D. Group and $7.50 \%$ of the cases in C.D.

In our study Electrolyte imbalance occurred in 1 Case (1.66\%) in the V.D Group on the first postnatal day and responded with IV fluid \& proper nutrition.

In our present study maternal death occurred in $3.3 \%$ of the cases in the V.D Group while there were no maternal deaths in the C.D. group. Both the mothers who died had a convulsion delivery interval more than 12 hrs. Menon et.al (15) in 1961 observed that maternal mortality increased with increase in first convulsion delivery interval.

It is observed in our study that an early decision for caesarean section either within $6 \mathrm{hrs}$ of admission or $12 \mathrm{hrs}$ of first fit whichever is earlier is crucial in improving the feto-maternal outcome in primigravida with antepartum eclampsia with more than 34 weeks of gestation.

From this study it is concluded that caesarean section if done promptly in these cases leads to more favourable feto-maternal outcome than conservative obstetrics management with expectant vaginal delivery in primigravida with eclampsia beyond 34 weeks of gestation with unfavourable cervix on admission.

Table - I : Distribution of study subjects as per their clinical profile ( $\mathrm{n}=100)$

\begin{tabular}{|c|c|c|c|}
\hline Parameters & N & Mean \pm SD & Range \\
\hline Age & 100 & $21.96 \pm 2.839$ & $16-30$ \\
\hline No. Of convulsion & 100 & $3.67 \pm 2.778$ & $1-13$ \\
\hline No. Of ANC Visit & 100 & $0.74 \pm 1.041$ & $0-3$ \\
\hline Glassgow coma scale & 100 & $12.14 \pm 2.252$ & $5-15$ \\
\hline Pulse (per min) & 100 & $80.76 \pm 13.417$ & $62-120$ \\
\hline SBP & 100 & $149.74 \pm 17.121$ & $120-200$ \\
\hline DBP & 100 & $97.60 \pm 13.701$ & $70-130$ \\
\hline Respiratory rate & 100 & $19.59 \pm 3.596$ & $12-30$ \\
\hline
\end{tabular}

Table - II : Distribution of study subjects according to mode of delivery $(\mathrm{N}=100)$

\begin{tabular}{|l|c|c|}
\hline Mode of Delivery & Number & Percentage \\
\hline Vaginal delivery & 60 & $60 \%$ \\
\hline Caesarean section & 40 & $40 \%$ \\
\hline Total & 100 & $100 \%$ \\
\hline
\end{tabular}

Table - III : Distribution of Gestational Age of study subjects according to mode of delivery $(\mathrm{n}=100)$

\begin{tabular}{|c|c|c|c|c|}
\hline \begin{tabular}{|l|c|} 
Gestational age (in \\
weeks)
\end{tabular} & $\begin{array}{c}\text { V.D. Group } \\
\text { No. (\%) }\end{array}$ & $\begin{array}{c}\text { CD Group } \\
\text { No. (\%) }\end{array}$ & $\begin{array}{c}\text { Total } \\
\text { No. \% }\end{array}$ & P-value \\
\cline { 1 - 4 } $34-37$ & $25(73.5)$ & $9(26.5)$ & $34(100)$ & \multirow{2}{*}{0.047} \\
\cline { 1 - 4 } $37-40$ & $35(53)$ & $31(47.0)$ & $66(100) 0.047$ & \\
\hline Total & $60(60 \%)$ & $40(40 \%)$ & $100(100 \%)$ & \\
\hline
\end{tabular}

Table - IV : Distribution of study population as per their indication for caesarean section $(\mathrm{n}=40)$

\begin{tabular}{|l|l|c|c|c|}
\hline \multicolumn{2}{|l|}{ Indication of CS } & No (N=40) & Percentage & Grand percentage \\
\hline Antepartum eclampsia per se & 4 & $10 \%$ & $10 \%$ \\
\hline \multirow{3}{*}{ Cervical factors } & Infavourable cx & 5 & $12.50 \%$ & \multirow{2}{*}{$35 \%$} \\
\cline { 2 - 4 } & Failed induction & 7 & $17.50 \%$ & \\
\cline { 2 - 4 } & Cervical dystocia & 2 & $5 \%$ & $30 \%$ \\
\hline \multirow{2}{*}{ Fetal distress } & 12 & $30 \%$ & $25 \%$ \\
\hline \multirow{3}{*}{ Abnormal labour } & CPD & 4 & $10 \%$ & \\
\cline { 2 - 4 } & Obstructed labour & 4 & $10 \%$ & $100 \%$ \\
\cline { 2 - 4 } & Malpresentation & 2 & $5 \%$ & $100 \%$ \\
\hline Total & & 40 & & \\
\hline
\end{tabular}


Table $-\mathbf{V}$ : Distribution of study population as per time interval between $1^{\text {st }}$ Convulsion and delivery with mode delivery $(\mathrm{n}=100)$

\begin{tabular}{|l|c|c|c|c|}
\hline $\begin{array}{c}\text { Convulsion delivery } \\
\text { interval (hrs) }\end{array}$ & VD Group No. (\%) & CD Group No. (\%) & Total No. (\%) & P-Value \\
\hline $0-6 \mathrm{Hrs}$ & $3(23.1)$ & $10(76.9)$ & $13(100.0)$ & \\
\hline $6-12 \mathrm{hrs}$ & $16(47.1)$ & $18(52.9)$ & $34(100.0)$ & \multirow{2}{*}{0.02} \\
\hline $12-18 \mathrm{hrs}$ & $20(74.1)$ & $7(25.9)$ & $27(100.0)$ & \\
\hline $18-24 \mathrm{Hrs}$ & $13(86.7)$ & $2(13.3)$ & $15(100.0)$ & \\
\hline$>24 \mathrm{hrs}$ & $8(72.7)$ & $3(27.3)$ & $11(100.0)$ & \\
\hline Total & $60(60.0)$ & $40(40.0)$ & $100(100.0)$ & \\
\hline
\end{tabular}

Table VI : Distribution of Perinatal outcome among patients among undergoing vaginal delivery (VD Group) and caesarean section (CD Group).

\begin{tabular}{|c|c|c|}
\hline Perinatal outcome & $\begin{array}{c}\text { VD group N = 62 } \\
\text { No. }(\boldsymbol{\%})\end{array}$ & $\begin{array}{c}\text { CD Group N = 41 } \\
\text { No. }(\%)\end{array}$ \\
\hline IUGR & $19(30.64)$ & $8(19.51)$ \\
\hline LBW & $9(14.51)$ & $5(12.20)$ \\
\hline Prematurity & $40(64.51)$ & $15(36.58)$ \\
\hline APGAR Score < 5 at 1 min & $28(45.16)$ & $14(34.14)$ \\
\hline Need for resuscitation & $15(24.19)$ & $4(9.75)$ \\
\hline Need for NICU stay & $26(41.93)$ & $12(29.26)$ \\
\hline Live birth & $50(80.64)$ & $40(97.56)$ \\
\hline Still birth & $12(19.35)$ & $1(2.43)$ \\
\hline Early neonatal death & $8(12.9)$ & $4(9.75)$ \\
\hline Un-corrected PNM & $20(32.25)$ & $5(12.19)$ \\
\hline IUD on adm. & $5(8.06)$ & $0(0.0)$ \\
\hline Corrected PNM & $15(24.19)$ & $5(12.19)$ \\
\hline
\end{tabular}

Table VII : Distribution of study population as per maternal complication according to mode of delivery (n $=100)$

\begin{tabular}{|c|c|c|}
\hline Complication & $\begin{array}{c}\text { VD Group (n=60) No. } \\
(\mathbf{\%})\end{array}$ & $\begin{array}{c}\text { CD Group (N=40) } \\
\text { No. }(\boldsymbol{\%})\end{array}$ \\
\hline PPH & $9(15 \%)$ & $1(2.50)$ \\
\hline Abruptio placentae & $2(3.33 \%)$ & $0(0.00)$ \\
\hline Renal Failure & $2(3.33 \%)$ & $0(0 \%)$ \\
\hline CVA & $4(6.66 \%)$ & $0(0 \%)$ \\
\hline Pulmonary Odema & $2(3.33 \%)$ & $0(0 \%)$ \\
\hline Fever & $5(8.33 \%)$ & $2(5 \%)$ \\
\hline Haematuria & $5(8.33 \%)$ & $3(7.50 \%)$ \\
\hline Electrolyte imbalance & $1(1.66 \%)$ & $0(0 \%)$ \\
\hline Total & $30(50 \%)$ & $6(15 \%)$ \\
\hline
\end{tabular}

Table - VIII : Distribution of maternal mortality according to mode of delivery $(\mathrm{n}=100)$

\begin{tabular}{|c|c|c|c|}
\hline \multirow{2}{*}{ Group } & \multirow{2}{*}{} & \multicolumn{2}{|c|}{ Maternal Death } \\
\cline { 3 - 4 } & & No. & $\%$ \\
\hline VD & 60 & 2 & 3.33 \\
\hline CD & 40 & 0 & 0.00 \\
\hline Total & 100 & 2 & 2 \\
\hline
\end{tabular}

\section{Referfence}

[1]. Dutta DC .Textbook of Obstetrics. 7th Ed. Kolkata: New Central Book Agency Pvt. Ltd.; 2011. p. $230-36$.

[2]. Cunningham FG, Lenevo KJ, Bloom SL, Hauth JC, Rouse DJ, Spong CY. Williams Obstetrics.24 ${ }^{\text {th }}$ Ed., McGraw Hill Co. Inc., 2014: 730- 70p.

[3]. Pal B, Geeta N, Vivek P. A study of eclampsia. JObstetGynecol. 1996 Feb; 46(1): 34-39.

[4]. Bhattacharya PK, Purkayastha S, Basu M, Robinsanath M. Caesarean section in eclampsia Still a dilemma. $J$ ObstetGynecol of India 1992 Feb; 42(1): 51-55.

[5]. Lopez-Llera M, Rubio Linares G, Hernandez Horta JL. Maternal mortality rates in eclampsia. Am J Obstet Gynecol. 1976 Jan 15 ; 124(2): 149-55.

[6]. Taner CE, Hakverdi AU, Aban M, Erden AC, Ozelbaykal U.Prevalence, management and outcome in eclampsia.Int J Gynaecol Obstet. 1996 Apr; 53(1): 1 1-5.

[7]. Bansal V. Maternal and perinatal outcome in Eclampsia. Abstract, free communication papers, 42nd All India Congress of Obstetrics\& Gynecology, 1998.

[8]. Low JJ, Yeo GS. Eclampsia- are we doing enough? Singapore MedJ. 1995 Oct; 36(5): 505-9.

[9]. Mundle S, Mullik T, Risk Factors in Pregnancy outcome in eclampsia. Abstracts Free Communication papers, 42 ${ }^{\text {nd }}$ All India Congress of Obstetrics \& Gynecology 1998.

[10]. Habeebullah S, Agarwal A, Swain S, Arora R. Impact of mode of delivery on maternal mortality in eclampsia. JIMA 1997 Apr; 95(4): 103-4,106.

[11]. Dandekar LM, Biren Sha, Eclampsia : Peripharal Hospital Experience. J of Obstet \& Gynaecol of India 1993 Feb ; 43 (1) : $42-44$

[12]. Witlin AG, Saade GR, Mattar F, Sibai BM. Risk factors for abruptio placentae and eclampsia : Analysis of 445 consecutively 
managed women with severe pre-eclampsia and eclampsia Am J Obstet Gynaecol. 1999 June ; 180 (6 pt 1) : 1322-9.

[13]. Eclampsia Trial Collaborative Group : which anticonvulsant for women with eclampsia ? Evidence from the collaborative eclampsia trial. Lancet. 1995 Jun 10 ; 345 (8963) : 1455-63.

[14]. Sheehan HL, Lynch JB (Ed) : Cerebral lesions in : Pathology of Toxemia of Pregnancy. Baltimore, Williams \& Wilkins.

[15]. Menon MK. Caesarean section in eclampsia. J Obstet Gynaecol Br Emp. 1955 April; 62(2): 283-7. 